\title{
Assessment of Night-Shift Effects on Nurses' Health in Intensive Care Units in Some Hospitals of Nineveh Governorate
}

\author{
Rami Ramadhan Allawa*
}

\begin{abstract}
Background and Objectives: Iraqi hospitals needs the services of nurses throughout the 24 hours including night time, and it is very necessary to study the impacts of night work on nurses in many aspects such as physical health and work performance for those nurses. The nurses' health who working at night shift is essential issue that it should be have to take in considered. The night shift work may have a negative impact on the individual's health and ability to function, thus affecting the services provided. Therefore the study aimed to assess the effect of night shift on nurses in intensive care units at some hospitals of Nineveh governorate.

Materials and Method: A descriptive study was conducted at five hospitals, which are Al-Salam hospital, Al-jumhory hospital, Ibn-Sena hospital, Al-hamdania hospital, and General Mosul hospital, (50) male and female nurses were chosen, A constructed questionnaire was used to collect the data from the $1^{\text {st }}$ January 2013 to $1^{\text {st }}$ March 2013. Data were analyze by using descriptive and inferential statistical (percentage, frequency, and chi-square).

Results: The results reveal that there are significant relationship between the working at night shift and exposure of the nurses to some problems such as sleep disorders (32\%), muscle strain $(64 \%)$, persistent tiredness (32\%), and exposure to needle stick injury (30\%).

Conclusion: the study concluded that nurses of all ages and of both gender are exposed to the risks of night shift work and these risks have negative impact on nurse's health. The majority of the nurses complained of a number of problems when working on night shift such as muscle strain, sleep disorders, tiredness, and occupational injuries.
\end{abstract}

Key Words: night shift, intensive care units, nurses.

\section{INTRODUCTION}

Several literature has shed light on the night shift impacts on the life of medical staff and health workers, particularly nurses, especially those working in night shift. literature has studied these effects against the physiological nature of the human being which affects their health (Abdalkader \& Hayajneh, 2008). In present study focuses on the nurses who work at night shifts and impact of night shift on the physical health, especially those who work in intensive care units. The night shift definition is different from country to country. In several countries is defines as night work means work performed after 18:00 and before 06:00 the next day (Kogi, 2001). That means that nurses are working 12 hours which called a 12-hour shift system. But here in Nineveh our governmental hospital, the situation and the definition of night shift is different they have not been used a 12-hour shift system. They define night shift as work performed after 2:00 PM and before 08:00 AM of the next day, which means a 18-hour shift system. The current study may help both nurses and administrators to understand some of the underlying effects of night shift on nurses, and their impact on nurse's life, clinical practices. The study may help the manager by giving them direction as to what steps should be taken to protect nurses from occupational hazards that caused by night shift in attempt to decrease nurses turnover, which negatively affect safety and effectiveness of services provided in intensive care units. The study aimed to assess the effect of night shift on nurses in intensive care units at some Nineveh hospitals governorate.

\section{MATERIALS AND METHOD}

A descriptive study was carried out at the Al-Salam Hospital, Al-jumhory Hospital, IbnSena Hospital, Al-Hamdania Hospital, and General Mosul Hospital. The study was conducted from the $1^{\text {st }}$ January 2013 to $1^{\text {st }}$ March 2013. A purposive sample of (50) nurses were chosen from these five hospitals during data

* Assistant Lecturer/College of Nursing/University of Mosul/Email: ramy_ramadan83@yahoo.com 
collection period in intensive care units. To study the effect of night shift on nurses, a constructed questionnaire was developed, and was validated by panel of experts, their opinions, suggestions and recommendations were depended to adapt and direct the questionnaire. It comprised of two part: demographic information's: this part presents the demographic data which was comprised of different items that include general information about nurses such as (Gender, Age, Educational level). In addition, information related to characteristics of night work such as (strenuousness of night shift, sleeping hours after end of night shift, methods to induce sleep after the night shift, workload during the night shift, problems experienced by nurses during the night shift, and exposure to occupational injuries during the night shift). Collecting data were along four weeks duration. This study was conducted on male and female nurses who working in intensive care units.

Data are analyzed through the application of descriptive statistics data analysis methods such as frequencies, percentages, and chi-square test. by using the Statistical Package of Social Science (SPSS / version 19).The probability value depended to indicate the significance was $(\mathrm{P} . \leq 0.05)$.

\section{RESULTS}

Table (1): Percent distribution of the demographical characteristics of the study subjects

\begin{tabular}{|c|c|c|c|c|c|}
\hline Gender & \multicolumn{2}{|c|}{ Male } & \multicolumn{3}{|c|}{ Female } \\
\hline Percentage & \multicolumn{2}{|c|}{$78 \%$} & \multicolumn{3}{|c|}{$22 \%$} \\
\hline Age & $20-24$ & $25-29$ & $30-34$ & $35-39$ & $40 \&$ more \\
\hline Percentage & $10 \%$ & $38 \%$ & $32 \%$ & $8 \%$ & $12 \%$ \\
\hline Level of education & school & preparatory & institute & & llege \\
\hline Percentage & $8 \%$ & $18 \%$ & $32 \%$ & & $2 \%$ \\
\hline
\end{tabular}

Table (2): Results of night shift effect on nurses in intensive care units

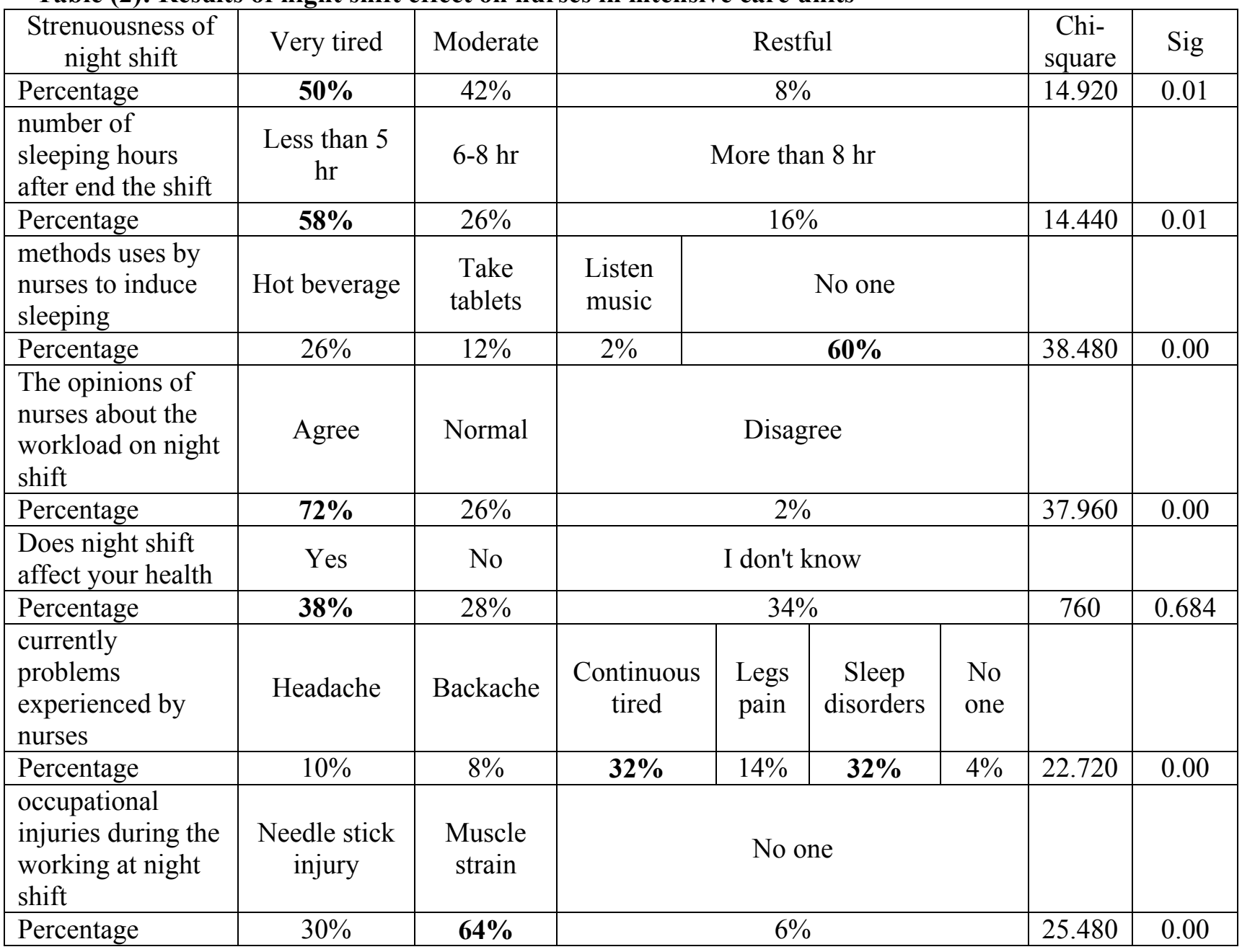




\section{DISCUSSION}

In this study table (2) $50 \%$ from the subjects feels very tired during working at night shift. This result come in agreement with the findings of previous study conducted by Abdalkader and Hayajneh (2008) which show that $(41 \%)$ from the nurses feel tired during the work at night shift. In this study (58\%) from the subjects were sleeping less than 5 hours after the end of shift, (26\%) sleeping 6-8 hours, and (16\%) sleeping more than 8 hours. This result is in agreement with previous study conducted by Yamanchi, et al (2009) which show that (61.3\%) from his sample sleep less than 5 hours, $(29 \%)$ sleep 6-7 hours, only (9.3\%) sleeps for eight hours or more after night shift. In this study finds that the percentage of nurses who used hot beverage to induce relaxation and sleep was $(26 \%)$, but $(12 \%)$ was used sleeping tablets, $(60 \%)$ don't take anything, and the rest $(2 \%)$ listen to music to induce sleeping. Moreover, the study demonstrate that the percentage of nurses who used sleeping tablets was (12\%) which mean that those nurses have real sleeping problems make them to use drug to induce sleep. This may confirm by a survey conducted by MADIDE (2003) which explores that (16\%) of the population of nurses who participates in the survey were takes sedations to induce sleep. Most of the nurses $(72 \%)$ who are participated in this study feels the night shift work had heavy workload, (26\%) moderate, and the rest $(2 \%)$ disagree. These results consider night work carries heavy workload for most nurses. It is important to know that this workload is not limited to physical but also the mental workload and this was confirmed by a study for Takashi et al (2001), who examined whether nurses can work at 12 hour working system, the result concluded that the system had significant physical and mental workload. In this study (38\%) from the subjects answered that working in night shift affected their health, (28\%) was answered no, (34\%) answered we do not know. This result is in agreement with study carried out by Koller (2010) which demonstrates that the majority of the nurses answered yes night shift affect at our health, forth of nurses responded with no it not affect at our health, just few of nurses respond that they do not know. In this study $(32 \%)$ suffering from sleep disorders or insomnia, (32\%) persistent or continuous tired during the work, (14\%) legs pain, (10\%) headache, $(8 \%)$ backache, and $(4 \%)$ none of the above. This results come in agreement with study conducted by Fietze et al (2009) that demonstrates that $(29.3 \%)$ from its subjects are loss of sleep or insomnia and $(21.3 \%)$ suffering from persistent tiredness, (20\%) backache, $(17.3 \%)$ frequent headache, $(6.6 \%)$ feet ailments, and $(5.3 \%)$ none of the above. Another heath related problem was that of exposure to occupational injuries and diseases, the results also shows that $(64 \%)$ of the participants suffered from muscle strain and (30\%) exposure to needle stick injury. A needle stick injury can occur if the nurse is too busy, drowsy or tired where she or he is likely to lose concentration and cause an accident, and in this condition the nurse become victim to acquired infectious serious diseases such as HIV and Hepatitis B or C viruses and other viral infections and this agreed with a study done by Isah et al (2013) state that night work have implications for the entire living sphere of mankind, thus health hazards and stresses of work itself. As well as intervening factors from outside the working life may influence and impair the state of health, and certainly this is a dangerous issue because it affecting at nurses work performance which will also affect at patient's health and quality of care.

\section{CONCLUSIONS}

This study concluded that nurses of all ages and both genders are exposed to the risks of night work and its negative impact on nurses health. The majority of the nurses complained of a number of problems when working on night shift such as muscle strain, sleep disorders, persistent tiredness, and exposure to occupational injuries. Just few nurses did not experience problems from the night shift.

\section{RECOMMENDATION}

It is better to distribute night shift among nurses systematically, the study recommends making periodic and continuous examinations to follow up nurses' physical health. Reduce the hours of night shift from (18hr) to (8hr) and increase the numbers of shifts to become three shifts A,B,C to give more rest to nurses, and increase the salary or spend additional fees for nurses who work at night shift.

\section{REFERENCES}

Abdalkader, R., and Hayajneh, R. (2008).Effect of Night Shift on Nurses Working in Intensive Care Units at Jordan University Hospital. European Journal of Scientific Research. 1. P.p.70-86 
Ingo, F., Karsten, K., Martin, G., Martin, H., Jan, G. P., Thomas, P. (2009). Effect of the first night shift period on sleep in young nurse students. Eur J Appl Physiol. P.p.107:707714.

Isah, E., Iyama, O., Imoudu, G. (2013). Health effects of night shift duty on nurses in a university teaching hospital in Benin city. Retrieved from essyisah@yahoo.co.uk on 20 Dec. 2012.

Kogi, K. (2001). Shift-work. International Encyclopedia of Ergonomics and Human Factors. 2. P.p. 1350-1353.

Koller, M. (2010). Occupational Health Services for Shift and Night Workers Applied Ergonmics. Eur J Appl Physiol. 27 (1). P.p.31-37.
Madide, S. (2003). Effects of Night Shift Schedules on Nurses Working in a Private Hospital in South Africa. European Journal of Scientific Research. P.p.402 407.

Takashi, O., AMM, K. A., Tomofumi, S., Toshihiro, I., Makoto, U., Masumi, M. and Sadahiko, N. (2001). Night-Shift Work Related Problems in Young Female Nurses in Japan. J Occup Health. 43. P.p. 150156.

Yamauchi, H., Iwamoto, M., Harada, N. (2009). Physiological Effects of Shift Work on Hospital Nurses. Medline abstract. 301 (12). P.p. 251-254. 